\title{
WTEERFAET TECNOLLGGCA
}

\section{COMUNICAÇÃO, TECNOLOGIA E SOCIEDADE: a importância da comunicação}

\author{
para a socialização do homem
}

COMMUNICATION, TECHNOLOGY AND SOCIETY: the importance of communication

for the socialization of man

Maria Aparecida Bovério - mariaboverio@ hotmail.com

Universidade Estadual Paulista (UNESP) - Campus de Rio Claro - SP -Brasil Faculdade de Tecnologia de Sertãozinho (FATEC) - SP - Brasil

DOI: 10.31510/infa.v15i1.327

\section{RESUMO}

Este artigo possui o objetivo de investigar a importância da comunicação e da tecnologia no processo de socialização do ser humano e sua inserção no mundo contemporâneo. A pesquisa adotou como metodologia a revisão bibliográfica e investigou, inicialmente, os aspectos teóricos que dizem respeito à linguagem, língua, fala e códigos de comunicação. Em seguida contemplou a importância da comunicação no processo de socialização e na aquisição cultural, bem como o respeito às diferentes culturas. Pesquisou, também, as tecnologias da comunicação e a sua relação com o homem contemporâneo. Abordou sobre os elementos básicos de semiótica e sua aplicabilidade: conceito de texto e hipertexto. Como resultados verificou-se que a comunicação e a tecnologia se fazem presentes na sociedade e compõem com assertiva o processo de socialização do homem. Conclui-se que são inerentes à cultura do homem e são considerados importantes elementos para se conviver harmoniosamente no meio social.

Palavras-chave: Comunicação. Tecnologia. Sociedade. Cultura.

\begin{abstract}
This article has the objective of investigating the importance of communication and technology in the process of socialization of the human being and its insertion into the contemporary world. The research adopted as a methodology the bibliographical revision and initially investigated the theoretical aspects that pertain to language, language, speech and communication codes. It then contemplated the importance of communication in the process of socialization and cultural acquisition, as well as respect for different cultures. He also researched communication technologies and his relationship with contemporary man. $\mathrm{He}$ approached about the basic elements of semiotics and its applicability: concept of text and hypertext. As a result, it was found that communication and technology are present in society and make up with assertive the process of socialization of man. It is concluded that they are inherent in the culture of man and are considered important elements to live harmoniously in the social environment.
\end{abstract}

Keywords: Communication. Technology. Society. Culture. 


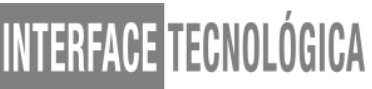

\section{INTRODUÇÃO}

Este artigo de caráter bibliográfico teve o objetivo de trazer uma contribuição sobre a temática que contempla a comunicação, tecnologia e sociedade e sua importância no processo de socialização do homem e sua inserção no mundo contemporâneo. A comunicação se faz presente na vida do homem, desde os primórdios da existência e sua importância é análoga ao ar que respiramos. Todos os dias nos comunicamos, de diferentes maneiras e métodos. Foi por meio da comunicação que o homem se tornou um ser social, adquiriu a cultura, os modos de pensamento, as crenças, os valores, os hábitos e os tabus, que foram transmitidos pela família, pelos amigos, pela educação escolar e pela nação. (BORDENAVE, 2010).

No entanto, a comunicação atual transcende àquela que foi, historicamente, utilizada. À comunicação trivial do homem foram acrescidas a tecnologia e, por meio dela, a comunicação tornou-se "sem fronteiras" em todos os âmbitos sociais. O homem atual estuda, conversa, faz reuniões e até cirurgias através de comunicações que se utilizam da tecnologia. Apesar disso, ainda existe falta de compreensão do homem naquilo que tange às riquíssimas formas de manifestações culturais, que se fazem presentes ao redor do mundo, expressas por conjuntos de características distintas, espirituais, materiais, intelectuais e afetivas que caracterizam uma sociedade ou um grupo social, seja pela música, dança linguagem, moda, artes, alimentação, comportamentos, consumo, lazer e tradições.

Assim, a temática em pauta é interessante para várias áreas: Letras, Comunicação, Tecnologias etc. e, por isso, houve a motivação de investiga-la. Para contemplar a amplitude a que o tema remete, este artigo foi organizado em seções. Na seção 2 são apresentados os procedimentos metodológicos, a seção 3 trata das questões básicas concernentes ao tema: linguagem, língua, fala e códigos de comunicação, a seção 4 contempla a importância da comunicação no processo de socialização e na aquisição cultural, bem como o respeito às diferenças culturais, na seção 5 são apresentadas as tecnologias da comunicação e sua relação com o homem contemporâneo, a seção 6 discorre sobre os elementos básicos de semiótica e sua aplicabilidade: conceito de texto e hipertexto e, para finalizar, a seção 7 apresenta as considerações finais.

\section{METODOLOGIA DE PESQUISA}

Metodologicamente, trata-se de um estudo de caráter bibliográfico que pautou -se na abordagem qualitativa. Pizzani et al (2012) explicam que a pesquisa bibliográfica é uma 
investigação científica que requer tempo, pois é um trabalho minucioso que despende dedicação e atenção por parte do pesquisador. A abordagem qualitativa foi escolhida porque por meio dela, em concordância com o que dispõe Minayo (2000), conseguem-se respostas mais particulares e obtêm-se opiniões mais precisas, informações e dados que expõem a realidade do tema estudado. A perspectiva deste tipo de abordagem, definida por Triviños (2011) é a busca pelo entendimento dos significados dos fenômenos para os sujeitos investigados, entendendo quais são as causas dentro deste contexto. Assim, a revisão bibliográfica permite a familiarização, em profundidade, com o assunto de interesse.

\section{LINGUAGEM, LÍNGUA, FALA E CÓDIGOS DE COMUNICAÇÃO}

O homem é um ser social que precisa se comunicar, quer recebendo, quer emitindo mensagens. Para que a comunicação ocorra se faz necessário o uso de um sistema de sinais devidamente organizado, denominado "linguagem". A linguagem é um processo de comunicação entre dois sujeitos, ao menos, sendo um o destinador ou emissor e o outro o destinatário ou receptor. Cada sujeito é, simultaneamente, o destinador e o destinatário de sua própria mensagem, visto que é capaz de ao mesmo tempo, emitir uma mensagem decifrandoa, e em princípio, não emite nada daquilo que não possa decifrar. (KRISTEVA, 2014).

Nos vários atos de comunicação de um homem, são emitidas uma série de mensagens e, também, recebidas, por meio de gestos, sons, sinais, oralidade, escrita, combinação de cores, através das tecnologias de comunicação e informação (TIC's) ou, ainda, da Língua Brasileira de Sinais (Libras) e do Braille ${ }^{1}$ etc. Isto nos permite afirmar que o homem utiliza vários "códigos" de comunicação. Pode-se definir códigos de comunicação como um conjunto de sinais utilizados na transmissão de uma mensagem. A "Língua" é considerada o mais importante dos códigos de comunicação, visto que ela representa a "parte social da linguagem", ou seja, ela pertence a uma comunidade ou grupo social, como por exemplo, a Língua Portuguesa. (MEDEIROS, 2010; KRISTEVA, 2014).

A Língua consiste num conjunto específico de códigos e palavras diversas, usados sob regras e leis de combinação permitindo que a mensagem seja transmitida de maneira compreensível. Apesar disso, existe a probabilidade de que a mensagem não seja

\footnotetext{
${ }^{1}$ Sistema de leitura e de escrita destinado às pessoas que possuem deficiência visual, em que as letras, os algarismos e os sinais gráficos são representados por uma combinação de seis pontos em relevo, que são lidos da esquerda para a direita, com uma ou ambas as mãos. (FERREIRA, 2010).
} 


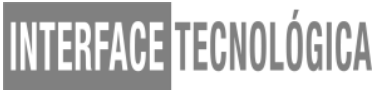

compreendida totalmente caso seja passada de forma incomum às regras previamente estabelecidas. (MEDEIROS, 2010).

Já a "fala" é individual e, portanto, expressa a maneira como um indivíduo se comunica oralmente, fazendo uso da linguagem verbal. Portanto, é comum que a fala seja afetada por costumes locais, vícios de linguagem relacionados ao ambiente que o indivíduo frequenta e as pessoas ao seu redor, bem como ao tipo de linguagem que estas usam para se comunicar. Nota-se que a fala passa por um processo de construção ao longo da vida e nela são agregados os aspectos pessoais e existenciais e, por isso, a fala pode distinguir-se bruscamente de um indivíduo a outro, de acordo com o contexto socioeconômico, político, cultural e educacional. Ou seja, a fala recebe a influência segundo seu nível de instrução do falante, idade, região, cultura, conhecimento e situação onde ocorre $\mathrm{o}$ ato da fala. (MEDEIROS, 2010; KRISTEVA, 2014).

Entretanto, é primordial considerar a existência de um conjunto de normas que estabelece o "padrão culto" de cada língua e recebe o nome de "gramática normativa". (MEDEIROS, 2010; KRISTEVA, 2014). Verifica-se, portanto, que há vários níveis de linguagem e, para efeitos didáticos, pode-se agrupá-los em basicamente dois: a) o coloquial (ou informal) e b) o culto (ou formal). O nível coloquial, geralmente, é utilizado nas situações diárias, de informalidade. O nível culto caracteriza-se por uma linguagem mais obediente às normas gramaticais, estando menos sujeito às variações. (KRISTEVA, 2014).

Embora as variações linguísticas estejam condicionadas pelas circunstâncias, a língua falada e a língua escrita cumprem sua finalidade, que é a comunicação. A língua escrita, conforme anteriormente mencionado, obedece a normas gramaticais e será sempre diferente da língua oral, que é mais solta, espontânea e livre, uma vez que, geralmente, é acompanhada de mímica e entonação, que preenchem importantes e significativos papéis nos processos cotidianos de comunicação. Mas, a língua oral é bem mais sujeita a falhas, ou seja, a linguagem empregada coloquialmente difere substancialmente do padrão culto, que deve seguir as normas gramaticais. (MEDEIROS, 2010; KRISTEVA, 2014).

$\mathrm{Na}$ sociedade, seja no âmbito pessoal ou profissional, o homem que possui o domínio eficiente da língua, em seus variados registros e em suas inesgotáveis possibilidades de variação, certamente tem uma das condições para o bom desempenho profissional e social. 


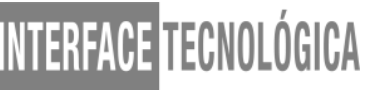

\section{A IMPORTÂNCIA DA COMUNICAÇÃO NO PROCESSO DE SOCIALIZAÇÃO E NA AQUISIÇÃO CULTURAL}

A cultura define-se como os modos de pensamento e ação do homem, suas crenças, religiões, valores, seus hábitos e tabus, adquiridos diariamente com os pais, a família, o grupo de amigos, na rua, no ambiente religioso, na escola, na vizinhança, enfim, por meio do convívio com seu entorno local, regional e com sua nação. (BORDENAVE, 2005). Os níveis de linguagem de um homem têm relação direta e intrínseca com sua cultura, que é definida por Ferreira (2010) como [...] instrução, saber, estudo.

A comunicação é o "canal" pelo qual o homem insere-se na sociedade e adota, assim, os padrões de vida de sua cultura. (BORDENAVE, 2005). De acordo com Medeiros (2010) etimologicamente, comunicação remete aos significados de tornar comum, de fazer saber, de trocar opiniões e isto implica em interação e troca de mensagens. Pode-se, ainda, encontrar os seguintes significados relacionados à palavra comunicação, no dicionário de Ferreira (2010): participar, fazer saber, pegar, transmitir, estar em comunicação, corresponder-se, propagar-se e transmitir-se. Ou seja, a comunicação é um processo de participação de experiências em vários campos do saber, que pode modificar a disposição mental das pessoas envolvidas durante o processo de comunicação. "No mundo moderno a palavra comunicação tornou-se lugar comum e transformou-se em força de extraordinária vitalidade na observação das relações humanas e no comportamento individual" (MARTINS; ZILBERKNOP, 2010, p.27).

Nas quatro últimas décadas, os cientistas aumentaram o interesse pelo estudo e os efeitos do processo de comunicação, iniciando-se com um estudo assistemático que se transformou em subsídios valiosos para outras ciências. Psicólogos, sociólogos, antropólogos empenharam-se em investigar e compreender sua atuação do processo de comunicação sobre os grupos humanos. Segundo Martins e Zilberknop (2010) a comunicação é um processo social e, por isso, sem ela a sociedade não existiria.

Nesse contexto, há um interesse de análises e reflexões teóricas sobre a linguagem, demonstradas por meio de várias correntes metodológicas. Há estudos que emergem da sociolinguística, que segundo Cunha e Cintra (2009) é o ramo da linguística que estuda a língua como fenômeno social e cultural. Tais estudos mostram que estas inter-relações são muito complexas e podem assumir diferentes formas. Em alguns casos faz mais sentido admitir uma relação direcional: a influência da sociedade na língua, ou da língua na sociedade. 


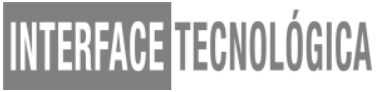

Cunha e Cintra (2009) explicam que é recente a concepção de língua como instrumento de comunicação social, maleável e diversificado em todos os seus aspectos, meio de expressão de indivíduos que vivem em sociedades também diversificadas social, cultural e geograficamente. Nesse sentido, uma língua histórica não é um sistema linguístico unitário, mas um conjunto de sistemas linguísticos, isto é, um diassistema, no qual se inter-relacionam diversos sistemas e subsistemas. Daí o uso de uma língua revestir-se de extrema complexidade, não podendo prescindir de uma delimitação precisa dos fatos analisados para controle das variáveis que atuam em todos os níveis, nos diversos eixos de diferenciação.

Por outro lado, existe a semiótica, que segundo a definição de Ferreira (2010) é a ciência dos modos de produção, de funcionamento e de recepção dos diferentes sistemas de sinais de comunicação entre indivíduos ou coletividades. De acordo com Santaella ${ }^{2}$ (2012) o termo "semiótica" vem da raiz grega semeion, que quer dizer signo, ou seja, semiótica é a ciência dos signos, a ciência geral de todas as linguagens (verbais e não verbais).

A "Semiótica da Cultura" discute e investiga os aspectos sociais, filosóficos e tecnológicos que, de alguma forma, têm influenciado sobre a produção sígnica de determinada cultura e dão conta dos processos de significação e de comunicação de um grupo social. Com fundamento na semiótica da cultura, pode-se afirmar que há diferentes tipos de produção cultural entendidos como processos de comunicação e de organização da informação no ambiente da cultura. A semiótica da cultura entende a cultura como “linguagem”, formas de expressão que vão além da esfera social e estão na cultura, abarcando todos os aspectos da vida. Dessa maneira, produzem significado no cotidiano e, por isso, há diversas formas de comunicação e diversas representações de grupos sociais em diferentes momentos históricos. (VELHO, 2009). Portanto, a linguística é a ciência da linguagem verbal (oral ou escrita), historicamente institucionalizada e a sociolinguística é o ramo da linguística que estuda a língua como aspecto social e cultural a partir do olhar da linguística.

A semiótica é a ciência de toda e qualquer linguagem (de todos os códigos de comunicação existentes). A semiótica entende que a Língua é aquela nativa, materna, pátria, mas essa não é a única e exclusiva forma de linguagem que somos capazes de produzir, criar, reproduzir, transformar e consumir, ou seja, ver, ouvir e ler para que possamos nos comunicar uns com os outros. O estar no mundo como indivíduos sociais que somos é mediado por uma rede intricada e plural de linguagem, isto é, comunicamo-nos através da leitura e/ou da

\footnotetext{
2 Maria Lucia Santaella é uma das principais divulgadoras da semiótica no Brasil e, por isso, optou-se, especialmente, por esta autora, ao tratar desta temática no artigo.
} 
produção de formas, volumes, massas, movimento, interações de forças. Além disso, somos leitores e produtores de dimensões e direções de linhas, traços, cores etc. Ou seja, também nos comunicamos e nos orientamos através de imagens, gráficos, sinais, setas, números, luzes, objetos, sons musicais, gestos, expressões, cheiro, tato, olhar, do sentir, do apalpar, etc. Nesse sentido, somos uma espécie tão complexa quanto são complexas e plurais as linguagens que nos constituem como seres simbólicos, isto é, seres de linguagens. (SANTAELLA, 2012).

Em todos os tempos grupos humanos recorreram a modos de expressão, de manifestação de sentido e de comunicação sociais divergentes da linguagem verbal institucionalizada, desde os desenhos nas grutas de Lascaux, os rituais de tribos primitivas, danças, músicas, cerimoniais, jogos, até as produções de arquiteturas e de objetos, além das formas de criação da linguagem que viemos a chamar de arte: desenhos, pinturas, esculturas, poética, cenografia etc. Assim, a linguagem verbal escrita não conheceu somente o modo de codificação alfabética, pois há outras formas de codificação escrita, diferentes da linguagem alfabeticamente articulada, tais como hieróglifos, pictogramas, ideogramas, formas estas que se limitam ao desenho. Pode-se afirmar, portanto, que há uma linguagem verbal, de sons que veiculam conceitos e que se articulam no aparelho fonador, sons estes que, no Ocidente, receberam uma tradução visual alfabética (linguagem escrita). Mas, existe, simultaneamente, uma enorme variedade de outras linguagens que também se constituem em sistemas sociais e históricos de representação do mundo. que inclui, inclusive, a linguagem dos surdos-mudos, a LIBRAS; dos que possuem deficiência visual, o Braille, o sistema codificado da moda, da culinária e tantos outros. (SANTAELLA, 2012).

Nas perspectivas apresentadas, não existe variedade linguística que possa ser considerada certa ou errada. As variedades podem ser consideradas adequadas ou inadequadas a uma determinada situação comunicativa. De acordo com essa adequação, a língua é considerada um poderoso instrumento de ação social. A linguagem que utilizamos não transmite somente nossas ideias, transmite também um conjunto de informações sobre quem somos socialmente: a região do país em que nascemos, nosso nível social, cultural e escolar, nossa formação, nossas características pessoais. Nesse sentido, a língua pode tanto facilitar quanto dificultar nosso relacionamento com as pessoas e a sociedade de modo geral, dependendo de quem é o nosso interlocutor. Assim, se faz necessário compreender a importância da linguagem do homem que também se manifesta por meio da cultura, em todos os aspectos da vida, inclusive no âmbito da comunicação social. Isso significa que, quando há a compreensão de que o homem é o reflexo da sua cultura e que, por isso, junto dele estão 
suas crenças, seus valores, seus hábitos e tabus, faz-se necessário estabelecer relações de respeito à diversidade cultural presente na sociedade e nas organizações.

\section{AS TECNOLOGIAS DA COMUNICAÇÃO E SUA RELAÇÃO COM O HOMEM CONTEMPORÂNEO}

Após a revolução industrial até a atualidade pode-se verificar que há invenções de máquinas capazes de produzir, armazenar e difundir linguagens, tais como: a fotografia, o cinema, os meios de impressão gráfica, o rádio, a TV, o computador e seus derivados, tablet, iphone, celulares etc. Toda essa tecnologia povoou o cotidiano com mensagens e informações que nos espreitam e nos esperam. Com um simples apertar de botões ou por meio de uma tela touch screen com um simples toque as notícias nos chegam da mesma forma - por analogia como nos chega a água, a luz, o wi-fi etc. Ora apenas recebemos mensagens que não ajudamos a produzir ou, com tanta tecnologia, muitas vezes as produzimos por meio de novas linguagens, como é o caso das linguagens que criam os programas, os softwares etc.

Atualmente, com o avanço da tecnologia existe, também, a indústria 4.0, na qual a linguagem da comunicação é feita quase que na totalidade entre as próprias máquinas, utilizando-se, inclusive, da tecnologia da linguagem computacional denominada "Internet das coisas", obviamente que necessitando de um ser humano para o seu desenvolvimento. Nesse contexto, "o mundo está no início de uma quarta revolução industrial e esta revolução está acontecendo devido à eliminação dos limites entre o mundo digital, o mundo físico, que são as coisas, e o mundo biológico, que somos nós”. (IEASP, 2016)

$\mathrm{Na}$ natureza, há a linguagem das flores, do vento, dos ruídos, dos sinais de energia vital emitidos pelo corpo e até mesmo a linguagem do próprio "silêncio", além do sonho, que segundo Freud (apud SANTAELLA, 2012) também se estrutura como linguagem. Para a semântica todo o fenômeno de cultura só funciona culturalmente porque é, também, um fenômeno de comunicação e esses fenômenos só se comunicam porque se estruturam como linguagem. Assim, pode-se afirmar que todo e qualquer fato cultural, toda e qualquer atividade ou prática social constituem-se como práticas significantes, isto é, práticas de produção de linguagem e de sentido. (SANTAELLA, 2012).

As linguagens estão no mundo e os seres humanos estão nas linguagens. A semiótica tem como objeto de investigação todas as linguagens possíveis e tem como objetivo o exame dos modos de constituição de todo e qualquer fenômeno como fenômeno de produção de 


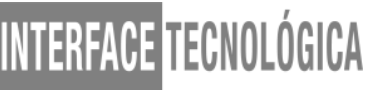

significado e de sentido. A própria noção de vida depende da existência de informação no sistema biológico, pois sem informação não há mensagem, não há planejamento e nem reprodução. E, no caso da vida, estes fenômenos são necessariamente ligados a uma linguagem, a uma ordenação obtida a partir de um compartimento armazenador de informação como o DNA (substância universal portadora de um código genético). Portanto, os dois ingredientes fundamentais da vida são: energia (que torna possíveis os processos dinâmicos) e informação (que comanda, controla, coordena, reproduz e, eventualmente, modifica e adapta o uso da energia. (SANTAELLA, 2012).

Todos os sistemas de linguagem tendem a se comportar como sistemas vivos, ou seja, eles se reproduzem, se readaptam, se transformam e se regeneram como as coisas vivas. Por isso a semiótica analisa as linguagens que vão desde a culinária até a psicanálise, passa pela meteorologia, pela anatomia, dá palpites ao cientista político e ao músico, um teorema matemático, um lamento de dor, ou uma ideia abstrata são objetos de análise da semiótica, do ponto de vista de investigação de sua linguagem, isto é, da ação de seu signo, essa é a “delimitação" de estudo da semiótica, tão só e apenas e isso já é muito. (SANTAELLA, 2012). Igualmente importantes são os recursos tecnológicos, os eletrônicos e os digitais que agregados aos recursos didáticos tradicionais também podem compor o repertório linguístico das pessoas. Nesse sentido, temos o texto tradicional, em sua estrutura já conhecida e o hipertexto que também é uma importante ferramenta de inclusão do indivíduo nos temas que circulam pelo mundo, por sua facilidade de acesso e amplitude de informações, apesar de sua falta de linearidade, que será abordado na seção 6.

\section{ELEMENTOS BÁSICOS DE SEMIÓTICA E SUA APLICABILIDADE: CONCEITO DE TEXTO E HIPERTEXTO}

Ferreira (2010) atribui como significado da palavra texto [...] conjunto das palavras de algum livro ou escrito [...]. De acordo com Medeiros (2010) pode-se definir texto como um tecido verbal estruturado de tal modo que as ideias formam um todo coeso, uno, coerente, em que todas as partes devem estar interligadas e manifestar um direcionamento único. Os elementos estruturais de um texto são: o saber partilhado, a informação nova, as provas, a conclusão, o tema e a referência. A palavra texto provém do latim textum, que significa “tecido, entrelaçamento". Há, portanto, uma razão etimológica que não devemos esquecer de que texto resulta de um trabalho, a ação de tecer, entrelaçar unidades e partes a fim de formar um todo. 


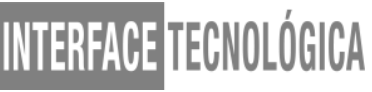

Com relação à palavra hipertexto, seu significado remete a uma sequência de texto que permite a remissão para outra localização (documento, arquivo, página da Internet, etc. (FERREIRA, 2010). O hipertexto é a apresentação de informações escritas, organizada de tal maneira que o leitor tem liberdade de escolher vários caminhos, a partir de sequências associativas possíveis entre blocos vinculados por remissões, sem estar preso a um encadeamento linear único. É uma forma de apresentação de informações em meio digital, na qual algum elemento (palavra, expressão ou imagem) é destacado e, quando acionado por um clique de mouse ou de touch screen, provoca a exibição de um novo hipertexto com informações relativas ao referido elemento, ou seja, hipertexto vem da hipermídia. (FERREIRA, 2010; KOCH, 2005).

Se por um lado, o hipertexto amplia as escolhas de caminhos no que diz respeito ao entendimento pelo leitor, das quais a escolha do caminho correto é atribuída à sua inteligência, por outro lado, o excesso de fragmentação textual pode deixar o leitor disperso e confuso. A pluritextualidade encontrada nos hipertextos se traduz pela dinamicidade de elementos sígnicos (texto, imagens, sons), que, uma vez bem organizados, podem beneficiar enormemente o leitor, ativando a leitura multissensorial e motivando o envolvimento deste para com o texto. (MARCUSCHI; XAVIER, 2004). A noção de hipertexto constitui um suporte linguístico-semiótico intensamente utilizado para estabelecer interações virtuais desterritorizadas. O termo designa uma escritura não sequencial e não-linear, que se ramifica e permite ao leitor virtual o acessamento praticamente ilimitado de outros textos, a partir de escolhas locais e sucessivas em tempo real. (KOCH, 2005).

No que diz respeito à multiplicidade de escolhas no texto a ser lido, esta enriquece o texto, aumentando as chances de compreensão do mesmo. O leitor do hipertexto é emancipado, pois sua compreensão final pode ir além daquela oferecida pelos textos tradicionais, independente da intenção do autor. A questão da autoria também é mencionada, já que o autor é dessacralizado graças às facilidades de publicação que são oferecidos pela Internet. O entendimento desses tipos de textos é cada vez mais necessário na nossa sociedade, pois eles acondicionaram os hábitos de leitura do homem. Além disso, exigem uma maturidade do leitor em relação ao texto já que este pode a qualquer hora comentar acerca do que foi lido, interagindo diretamente com o autor do texto em questão. (MARCUSCHI; XAVIER, 2004). 


\section{CONSIDERAÇÕES FINAIS}

Diante do contexto apresentado nesse artigo pode-se concluir que a comunicação se confunde com a própria vida, pois é uma necessidade básica do ser humano, do homem social. Verificou-se, ainda, que o processo de comunicação é inerente à socialização do homem e sua inserção no mundo contemporâneo.

Assim a compreensão das teorias que compõem o universo sígnico se torna essencial para entender sobre a importância da comunicação no processo de socialização e na aquisição cultural. No que tange às tecnologias da comunicação e a sua relação com o homem contemporâneo, verifica-se a importância de se adquirir este tipo de conhecimento, uma vez que as tecnologias estão presentes no cotidiano do homem. O próprio hipertexto é oriundo da hipermídia, que por sua vez é oriunda das tecnologias.

Pode-se concluir, finalmente, que a linguagem e a cultura se fazem presentes no processo comunicativo, que por sua vez "não possui fronteiras" e isso requer o respeito às diferenças culturais. Com essas considerações, pode-se inferir que a comunicação e a tecnologia se fazem presentes na sociedade, são inerentes à cultura do homem, e são considerados importantes elementos para se conviver harmoniosamente.

\section{REFERÊNCIAS}

BORDENAVE, Juan Díaz E. O que é comunicação. São Paulo: Brasiliense, 2005.

CUNHA, Celso; CINTRA, Lindley. Nova gramática do português contemporâneo: de acordo com a nova ortografia. 5. ed. São Paulo: Lexikon, 2009.

FERREIRA, Aurélio Buarque de Holanda. Dicionário Aurélio da língua portuguesa. 5. ed. São Paulo: Positivo, 2010.

INSTITUTO DE ESTUDOS AVANÇADOS DA USP - SP (IEASP). Iniciativas 4.0 Aplicações de Internet das Coisas no Agronegócio, Saúde e Indústria. Disponível em: < http://www.iea.usp.br/eventos/iniciativas-4-0-2013-aplicacoes-de-internet-das-coisas-noagronegocio-saude-e-industria>. Acesso em: 15 fev. 2018.

KRISTEVA, Júlia. História da linguagem. Lisboa, Edições 70, 2014. ISBN 9789724414171. $336 \mathrm{p}$.

KOCH, Ingedore G. Villaça. Desvendando os segredos do texto. 4. ed. São Paulo: Cortez, 2005. 


\section{WTEERFAET TECNOLLGGCA}

MARCUSCHI, Luiz Antonio; XAVIER, Antônio Carlos (Orgs.). Hipertexto e gêneros digitais. Rio de Janeiro: Lucerna, 2004.

MARTINS, Dileta Silveira; ZILBERKNOP, Lúbia Scliar. Português Instrumental: de acordo com as atuais normas da ABTN. 29. ed. São Paulo: Atlas, 2010.

MEDEIROS, João Bosco. Português Instrumental: contém técnicas de elaboração de trabalho de conclusão de curso (TCC). 9. ed. São Paulo: Atlas, 2010.

MINAYO, Maria Cecília de Souza (Org.) Pesquisa social: teoria, método e criatividade. 16 ed. Petrópolis: Vozes, 2000.

PIZZANI, Luciana et al. A arte da pesquisa bibliográfica na busca do conhecimento. In: Revista Digital de Biblioteconomia e Ciência da Informação, Campinas, São Paulo, v.10, n. 1, p.53-66, jul. 2012. Disponível em:

<https://periodicos.sbu.unicamp.br/ojs/index.php/rdbci/article/view/1896>. Acesso em: 06 jan. 2018.

SANTAELLA, Lúcia. O que é semiótica. São Paulo: Brasiliense, 2012.

TRIVIÑOS. Augusto N. S. Introdução à pesquisa em Ciências Sociais: a pesquisa qualitativa em educação. São Paulo: Atlas, 2011.

VELHO, Ana Paula Machado. A semiótica da cultura: apontamentos para uma metodologia de análise da comunicação. Rev. Estud. Comun., Curitiba, v. 10, n. 23, p. 249-257, set./dez. 2009. 